\title{
CORTANDO A CERCA: UMA ESCOLA DO CAMPO FRENTE À MULTICULTURALIDADE CONTEMPORÂNEA
}

\author{
Lydia Maria Assis Brasil Valentini ${ }^{1}$, Jefferson Marçal Rocha ${ }^{2}$ \\ ${ }^{1}$ Pedagoga da Secretaria Municipal de Educação de São Gabriel, Especialista em Criança e Adolescente em Situação de \\ risco (UNIFRA/SM); Pós-graduada em nível de Especialização em Educação: Interdisciplinaridade e Transversalidade \\ (UNIPAMPA Campus SG). Iydiaabrasil@yahoo.com.br \\ ${ }^{2}$ Professor adjunto da Universidade Federal do Pampa \\ jeffersonrocha@unipampa.edu.br
}

Um dia, pela força de nosso trabalho e de nossa luta, cortamos os arames farpados do latifúndio e entramos nele; mas quando nele chegamos, descobrimos que existem outros arames farpados, como o arame da nossa ignorância, e então ali eu percebi, melhor ainda, naquele dia, que quanto mais ignorantes, quanto mais inocentes formos diante do mundo, tanto melhor para os donos do mundo, $e$ quanto mais sabidos, no sentido de conhecer, tanto mais medrosos ficarão os donos do mundo. ${ }^{3}$

\section{RESUMO}

A escola brasileira, que a partir da Constituição de 1988 se propõe a conviver democraticamente em uma sociedade plural, tem como principal desafio reconhecer sua diversidade e riqueza, proporcionando condições de superação a qualquer tipo de discriminação. Neste sentido é na escola, enquanto espaço público, que todos os brasileiros primeiro se deparam com a diferença. $O$ objetivo deste artigo é analisar como a inclusão do Tema Transversal Pluralidade Cultural, prevista no Parâmetro Curricular Nacional, é tratada. A escola observada localiza-se no interior do município de São Gabriel/RS, tendo como grande parte dos alunos os filhos de agricultores assentados. Para tanto, realizaram-se pesquisa bibliográfica, observações de práticas pedagógicas, pesquisa, análise documental e entrevistas. A análise dos dados demonstra a necessidade de uma maior aproximação entre a execução das políticas públicas e a realidade da prática pedagógica local. Efetivando, assim, a escola como elemento agregador, que não só reconhece e valoriza a diversidade como parte inseparável da identidade e trajetória de seus educandos, mas também é capaz de superar a discriminação.

Palavras-chave: Pluralidade Cultural, Escola Rural, Educação Plural, Inclusão.

\section{ABSTRACT}

The Brazilian educational system has had, since the 1988's Constitution, the purpose of living in a democratic and plural society. Thus, it has as its main aim to recognize its diversity and cultural richness, searching for the necessary conditions to avoid all kinds of discrimination. It is in the school -exercised as a public dominium- that Brazilians first get confronted with the difference.

\footnotetext{
${ }^{3}$ Depoimento de um alfabetizador e camponês sem terra em um assentamento no Rio Grande do Sul (FREIRE, 2004) 
The purpose of this paper is to analyze how the inclusion of the Theme Transversality Cultural Plurality (parts of the National Curricular Parameter) is done. The school observed is located in the countryside of São Gabriel/RS County and most of its students are the children of the so called Sem Terra (landless people movement, known as MST). The research was based on bibliographical research, observation on pedagogical practice, research, documental analyses and interviews. The analyses of the data showed the necessity of an effective approach between public policies execution and the reality of the local pedagogical practices. So that the school can be a permanent unifying element which not only recognizes and values the diversity as an inseparable part of the student's identity and its life trajectories, but is also able to overcome discrimination.

Keywords: Cultural Plurality, Rural School, Plural Education, Inclusion.

\section{INTRODUÇÃO}

Este artigo analisa a inclusão do Tema Transversal Pluralidade Cultural em uma escola rural, localizada no interior do município de São Gabriel, RS. No trabalho, busca-se compreender como o tema transversal é tratado nesta Escola por meio de pesquisa bibliográfica, observações de práticas pedagógicas, pesquisa documental, entrevistas com equipe diretiva, educadores, funcionários e profissionais de órgãos públicos que atuam na região onde se localiza a escola, tais como, EMATER (Associação Rio-grandense de Empreendimentos de Assistência Técnica e Extensão Rural), IPHAN (Instituto do Patrimônio Histórico e Artístico Nacional) e Secretarias de Educação, do Meio Ambiente, de Saúde e de Assistência Social do município de São Gabriel, RS.

A opção temática é pontual nesta escola, uma vez que a mesma é marcada pela necessidade de se combater, através da educação formal e não formal, o preconceito em relação ao outro, pois o trabalho com a pluralidade cultural em uma escola rural deverá estar fundamentado em atividades que promovam a dignidade humana, cabendo à escola o papel de reconhecimento e de valorização da diversidade que envolve seus componentes.

O tema Educação na zona rural sugere a análise de situações de vulnerabilidade nas famílias que ali vivem, seja na esfera política, socioeconômica ou cultural. Os critérios considerados como situações de possível exclusão social foram os fatores distância (casa-escola-cidade), acessibilidade a serviços públicos, educação de qualidade (que inclui acesso a informática, biblioteca atualizada, laboratórios, formação e capacitação continuada para professores, dentre outros $)^{4}$. Deve-se ressaltar que os educandos oriundos das famílias assentadas, atendidos por esta escola, possuem uma trajetória familiar distinta das outras famílias que ali se encontram, pois enfrentam obstáculos que incluem moradia precária, escassez de oportunidades de emprego e outras situações desfavoráveis que dificultam até sua sobrevivência.

Além disso, ainda enfrentam a discriminação da mídia formal, que se opõe à reforma agrária realizada pelo Estado, fator que vem a dificultar sua aceitabilidade na sociedade do município.

A bibliografia utilizada envolve áreas que se articulam à Educação e à História Cultural, como Antropologia, Sociologia e Economia. Para caracterização da temática educação, foram utilizados especialmente os textos de Hanna Arendt (1978), Paulo Freire (2005) e a legislação federal (especificamente a LDBEN (Lei de Diretrizes e Bases da Educação Nacional) (BRASIL, 1996)), CF (Constituição da República Federativa do Brasil) (BRASIL, 1988) e PCNs (Parâmetros Curriculares Nacionais) (BRASIL, 1997). Em relação a

\footnotetext{
${ }^{4}$ Foi priorizado neste artigo o tema sobre a educação na zona rural pelo fato de ter dedicado alguns anos de minha vida profissional ao trabalho socioeducativo com crianças e adolescentes em situação de vulnerabilidade social, junto à Prefeitura do Município de São Gabriel, numa parceria entre a Secretaria de Assistência Social e a Secretaria Municipal de Educação. 
concepções culturais, as referências são Nestor Canclini (2008) e Sandra Pesavento (2002). O trabalho tem interfaces com áreas da Antropologia (LARAIA, 2007; MELATTI, 2007; EAGLETON, 2005; FONSECA; TERTO JR; ALVES, 2004; PETRINI, 2003), Sociologia (BAUMAN, 2004; BRUM, 2006) e Economia (ROCHA, 2011; SILVA, 2009).

Nosso recorte espacial é o município de São Gabriel. Este município pertence à região centro-oeste do Rio Grande do Sul e possui uma população de aproximadamente 60.425 habitantes, distribuídos em uma população urbana de 53.775 e população rural de 6.650 habitantes (FUNDAÇÃO DE ECONOMIA E ESTATíSTICA, 2010), com área territorial de $5.020 \mathrm{~km}$. A tradição da pecuária é forte na dinâmica da produção do espaço desta cidade, bem como a produção agrícola. Dentro do contexto da reprodução capitalista, encontram-se latifúndios de grandes extensões de terra e centenas de cabeças de gado, concentrados na mão de poucos proprietários, o que caracteriza o perfil social e econômico da região da Campanha (PESAVENTO, 2002).

Considerando que o espaço localizado entrelaça-se ao global a partir da contemporaneidade dos temas e discussões que são pautados no processo histórico, que é dinâmico e carregado de forças vivas que não permitem uma visão de futuro sem desdobrar continuamente os laços passados, cabe evidenciar que em uma região tradicionalmente de latifúndios, os novos atores sociais advindos dos assentamentos rurais, proporcionam uma nova reflexão sobre práticas e posturas educacionais. A escola de campo, analisada neste trabalho, faz parte de um conjunto de seis Escolas Polo ${ }^{5}$, que atendem do 10 ano à $8^{a}$ série e duas multisseriadas $^{6}$ (10 a 40 ano), e está localizada em um distrito a $75 \mathrm{~km}$ da sede do município, com acesso e trafegabilidade regular. Tanto educadores quanto educandos se deslocam à escola no mesmo transporte escolar. Com um total de 117 alunos, funciona em dias alternados (segunda, quarta e sexta) com aulas pela manhã e tarde. A turma de 4으스, foco da pesquisa, é formada por 14 educandos.

A Escola Polo analisada iniciou seu funcionamento em março de 1999 , em regime integral, com a finalidade de atender alunos de duas escolas próximas que apresentavam carência de espaço físico. A função principal de sua implementação foi atender a demanda dos filhos de colonos/agricultores assentados na região, oriundos da reforma agrária do Estado (de acordo com o Parecer №1064/2001 do Conselho Estadual de Educação do Estado do Rio Grande do Sul). A infraestrutura da escola apresenta boas condições de manutenção, com adequado espaço físico para o desenvolvimento de atividades educativas necessárias, instalações arejadas e apropriada iluminação.

\section{REFERENCIAL TEÓRICO}

\section{Aldeia Global e Cultura Local}

A sociedade contemporânea vive sob a égide da globalização mundial. A veiculação de informações passou a ser imediata. Este acesso renovado constantemente reforça a relação de interdependência entre os povos e evidencia as discrepâncias sociais. De acordo com Rocha (2011), as maravilhosas parafernálias que proporcionam conforto e satisfação pessoal são aproveitadas por uma minoria, os mais abastados. Neste contexto, o capitalismo impõe à contemporaneidade seres humanos competitivos e voltados ao consumo a qualquer custo, passando este a ser sinônimo de sucesso e felicidade. De outro lado, a maioria da população não possui acesso nem ao saneamento básico e, menos ainda, a uma alimentação que garanta o mínimo de

\footnotetext{
${ }^{5}$ Escola Polo são escolas nuclearizadas que se originaram da desativação de escolas com carência de espaço físico próximas, priorizando qualidade no ensino e aperfeiçoamento nas condições de vida do aluno de zona rural.

${ }^{6}$ Prática de ensino onde se reúnem várias séries/anos em um mesmo espaço.

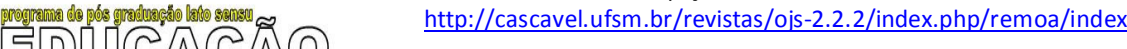


calorias diárias, ou uma educação digna, sobrando, para a maioria, apenas escassez de recursos e exclusão do mundo laboral.

Nesta grande aldeia, onde convivem povos de pequenas e grandes regiões mundiais, ricas e pobres, 0 sentido de democracia sofre tensões e desafios que expõem conflitos entre o local e o global, o universal e o singular, onde o cidadão passou a ser cidadão do mundo, situação que, muitas vezes, causa a perda de sua individualidade regional, o seu caráter único formado a partir de sua história comunitária. Nesta progressiva sociedade mundializada, parece que o local deixou de ser o mundo. O global, de acordo com Boaventura Santos (2000), é o local só que sem paredes. Destaca-se que se tornam cada vez mais vivas as formas de se pensar que o local deixa de ser exclusivamente local, passando também a ser global. Para Milton Santos (2003), ao contrário do que a lógica meramente econômica impõe ao local, a sua reação cultural pode se constituir justamente na sua globalização, pois as oportunidades de se conhecer outras culturas transforma a vida local em uma vida revalorizada. É a radicalização democrática da informação, que transformará o local também em global. Não é possível, portanto, viver sem as interferências desta globalização e, ainda que seja possível viver sem reconhecer diferenças entre culturas, não considerando uma única cultura dominante, é necessário o reconhecimento das diferenças internas de cada cultura.

Ao discorrer sobre concepções de cultura(s), devemos ficar atentos às diferenças de terminologias que envolvem raça e etnia, onde estas, muitas vezes, confundem-se nas relações entre o branco, o índio e o negro. De acordo com Melatti (2007), as características culturais podem ser modificadas ou abandonadas, as raciais não, nascendo daí as raízes do preconceito - o racismo, em uma visão popular e que não deriva de qualquer reflexão científica.

Entender as multifacetadas culturas a partir do conhecimento das ciências faz-se necessário para a reformulação de currículos no empreendimento de reformas educacionais, tanto em âmbito local como mundial. Os filhos dessa aldeia que formam as escolas ficam expostos, de alguma forma, aos impactos de políticas dominantes, pois a educação neste contexto sofre enfrentamentos diretos, quando se dilui na sociedade de consumidores caracterizada pela banalização de valores, tendência a isolamento e fragilidade nas relações afetivas, tanto nas familiares quanto nas demais (BAUMAN, 2004). Ressalta-se, neste momento, a importância de uma educação construída para e pelo local onde vivem estes educandos, valorizando a condição de pertencimento.

Devido à complexidade da questão, por falta de consenso (ou de conhecimento) quanto às definições que caracterizam o mundo contemporâneo, as dificuldades de se trabalhar na escola considerando estas concepções tornam o ensino descontextualizado, sem vínculos entre conhecimentos escolares e vida pessoal e cultural dos educandos. O próprio conceito de cultura é considerado por Eagleton (2005) como uma das expressões mais complexas da nossa língua, cuja compreensão envolve discussões de intermináveis reflexões, pois está atrelada a compreensão da natureza humana.

A cultura, ainda de acordo com Laraia (2008), para muito além de um complexo de comportamentos concretos, configura-se em um conjunto de mecanismos que governam o comportamento, portanto a criança está apta, ao nascer, para ser socializada em qualquer cultura existente.

A pluralidade cultural nas escolas se dá através da multiplicidade de grupos sociais distintos, o que é de extrema relevância, pois seu reconhecimento visa à tolerância entre os povos e à preservação do direito humano à cultura, legítimo a todas as etnias. Esta temática expõe o fato de não haver diferenças de classe, e sim de cultura de grupos. Cultura, de acordo com Freire (1979), é tudo o que pode ser criado pelo homem, tanto uma poesia como uma frase de saudação, constantemente recriando e não repetindo. Daí o conceito de diversidade ser a expressão de diferentes culturas, diferentemente organizadas politicamente, configurando o modo de produção capitalista. Nos PCNs, esta questão é abordada da seguinte forma: 
Em uma proposta curricular voltada para a cidadania, o tema da Pluralidade Cultural ganha especial significado ao propiciar elementos para que a criança estabeleça relações entre o equilíbrio democrático, a consolidação do pleno cumprimento de direitos, a coexistência de diferentes grupos e comunidades étnicas e culturais, e sua própria vida. A organização social dos grupos humanos inclui organizações políticas diversificadas, caracterizadas pelos fundamentos dados pela visão de mundo de cada grupo. Estruturam-se, assim, diferentes tipos de liderança e coordenação.

(...) Um ponto importante, ao tratar da organização política, é o que se refere a instituições voltadas para o bem comum. Poderá ser trabalhada de maneira fértil a percepção de como o pluralismo político e a pluralidade cultural se entrelaçam. Entender como se passa da organização comunitária para a busca dos interesses gerais da sociedade, como se estrutura politicamente tal complexidade, cooperará para a compreensão do significado de Estado. Assim, ao tratar em História da organização do estado, esse conteúdo poderá ser enfocado, mostrando como há instituições sociopolíticas constituídas por representantes de diferentes grupos e comunidades, tendo em comum a prática democrática. (BRASIL, 2001, p.81-82)

Cabe ressaltar dessa forma, a necessidade de ampliação de espaços de articulação com a comunidade, a fim de garantir a construção de uma identidade comum, respeitando individualidades. E é a partir dessa premissa que se enfrenta o enorme obstáculo, o desafio de conviver com justiça e solidariedade numa grande comunidade humana, com todas as pessoas e culturas humanizadoras, sem permitir que essa aldeia global se transforme numa voraz selva global (ZITKOSKY; TROMBETA, 2011). Constitui-se tarefa do educador o sacrifício hercúleo de contextualizar a dinâmica global com os aspectos históricos/ culturais de seus educandos.

\section{Política educacional: Cidadania e direitos humanos}

O ideal de sociedade no Brasil está fundamentado na CF (1988), pautado na garantia democrática da dignidade humana e da liberdade, na busca por uma vida mais justa, mais solidária, sem preconceitos ou quaisquer outras formas de discriminação. Incluem-se neste sentido as comunidades rurais, mobilizando a população em torno de garantia de direitos sociais e políticos e oportunizando o acesso de todos os brasileiros à educação escolar. Este princípio é uma tentativa de superação de um vício histórico e burocrático de atendimento homogêneo e sem diferenças a todo cidadão brasileiro. No Brasil, conforme dados do IBGE/PNAD $2004^{7}$, mais de 800 mil crianças de 7 a 14 anos estão fora das salas de aula. Dessas crianças, cerca de 500 mil são negras, destacando-se a escolarização mais alta entre as meninas brancas. A proporção de crianças e adolescentes negros fora da escola é $30 \%$ maior que a média nacional e duas vezes maior que a proporção de crianças brancas que não estudam. Já entre as crianças indígenas, as chances de estar fora da escola aumentam em quatro vezes em relação às crianças brancas. A pobreza infantil no Brasil tem cor. Entre as crianças negras, a pobreza é quase duas vezes maior que entre as brancas e, entre as indígenas, esta situação é ainda pior. Este cenário exige a elaboração e implementação de estratégias de acesso, permanência e aprendizagem específicos, que contemplem conteúdos que valorizem a cultura e a diversidade e promovam a não discriminação de gênero, raça e etnia.

Neste contexto, a educação do campo passa a ser entendida como segmento específico, com implicações sociais e pedagógicas próprias. Ressalta-se aqui a necessidade de políticas, ações e serviços

\footnotetext{
${ }^{7}$ Conforme o documento Desigualdades Raciais e de Gênero entre Crianças, Adolescentes e Mulheres no Brasil, no contexto dos Objetivos de Desenvolvimento do Milênio. Disponível em: <http://www.unifem.org.br/sites/700/710/00000163.pdf> Acesso em: 9 fev.2012. 
regionalizados, que considerem as condições locais, seu contexto cultural e ambiental, notadamente nas áreas rurais - caso das escolas de São Gabriel, onde convivem comunidades quilombolas, afrodescendentes e indígenas. Estes cidadãos brasileiros chegam, em muitos casos, a viver em condições sub-humanas, dentre os quais se incluem grande número de famílias de assentados que sobrevivem na mais extensa miséria. O MEC oferece propostas educacionais com o objetivo de promover uma educação pautada em princípios éticos fundamentados na Declaração dos Direitos Humanos e no exercício da democracia representativa, porém apresenta algumas contradições relacionadas à realidade do campo, que compromete sua eficácia devido as adversidades existentes neste meio.

Estudos detalhados sobre as várias etnias nativas nas Américas que constam no documento RS Índio Cartografias sobre a produção do conhecimento (SILVA; PENNA; CARNEIRO, 2009) reconhecem a riqueza da cultura indígena, incluindo temáticas específicas como a espiritualidade indígena; as relações cosmológicas e territoriais; as formas de organização social e política dos grupos étnicos; a língua e os mitos nas celebrações; as estratégias de ensino indígena; as influências da cultura indígena na tradição gaúcha; os movimentos sociais indígenas; os Guarani, os Kaingang e os Charrua na atualidade; o mapeamento urbano e rural e seus desdobramentos nas políticas públicas de garantia de direitos humanos dos povos indígenas, demonstrando que a competência das comunidades em construir o novo desvenda a marca da cultura nas identidades nacionais.

Quanto aos afrodescendentes, a valorização de um currículo escolar eurocêntrico que privilegia a cultura branca, reflete-se em situações de discriminação racial e preconceito, "produto histórico da escravidão e do sistema racial dominante no mundo, e de forma sutil na sociedade brasileira por consequência do mito da democracia racial" (FONSECA; TERTO JR; ALVES, 2004, p. 254). Esta expressão refere-se às relações raciais no Brasil, simulando uma suposta convivência harmoniosa entre negros e brancos, modo articulador do mito fundador da sociabilidade brasileira. Diante deste quadro discriminatório, a Escola por não contemplar de maneira equilibrada as contribuições culturais no sistema educacional, buscou inovar a partir de 2003, aprovando a Lei 10.639/03 (BRASIL, 2003) que torna obrigatório o ensino de História e Cultura Africana e Afro-Brasileira nas escolas de Ensino Fundamental e Médio, substituída, em 2008, pela Lei 11.645/08 (BRASIL, 2008) que inclui também o ensino de História e Cultura Indígena. Essas leis alteram a LDB e têm por objetivo promover uma educação que reconhece e valoriza a diversidade, comprometida com as origens do povo brasileiro.

A questão que se coloca é saber se esta inovação, ao tratar da disciplina de História, realmente mudou a forma do educando ter acesso a história, a sua história. Efetivamente, mudaram as formas de transmitir a influência das diversas culturas que formaram o povo brasileiro? E quanto ao educador, estava ou está preparado para trabalhar a nova proposta pedagógica?

Cumpre ao Estado fazer valer a tão sonhada cidadania, reconhecendo-os como sujeitos de direitos, considerando sua trajetória social e histórica, em diferentes tempos e em distintas condições sociais. Infelizmente, estes pressupostos que já estavam subentendidos na CF de 1988 correspondem muito mais a metas propostas por políticas governamentais do que ações e práticas reais efetivadas.

Uma escola efetivamente estará contribuindo com novas concepções do mundo vivido, alcançando a construção de identidades mais plurais, solidárias e que promovam o combate ao preconceito historicamente impregnado, quando descobrir que a história local de seus educandos deverá estar entrelaçada com a história do seu bairro, do seu estado, da América Latina e do mundo.

Considera-se aqui o principal desafio para o educador nessa nova dinâmica social é, concordando com a perspectiva de Zitkosky e Trombetta (2001), equilibrar essa tensão entre a unidade e a diversidade, no que diz respeito às diferenças. Se por um lado a política educacional tem a necessidade de atender particularidades locais, por outro ela deve considerar padrões gerais e o que é semelhante. 


\title{
Temas Transversais como prática de ensino
}

Ao se tratar de temáticas relativas a práticas educacionais atuais, temos que levar em conta, necessariamente, uma compreensão da realidade social vivida, tanto de forma individual como coletiva. Para sustentar esta proposta, os Temas Transversais se apresentam como suporte, como uma metodologia de ensino que alie os conteúdos com a vivência do educando, pois busca, nas questões presentes na vida cotidiana, temáticas para serem incorporadas ao trabalho didático do educador. Temas como ética, pluralidade cultural, meio ambiente, saúde, orientação sexual e consumo e trabalho apresentam-se como desafio para as escolas, à medida que trazem situações reais para serem contextualizadas com os componentes curriculares, abrindo-se a escola para o diálogo e para o debate. A perspectiva transversal deve permear toda a prática educativa que envolve a relação entre educandos, educadores e comunidade escolar, pois as crianças se desenvolvem na interação com o outro e na troca de experiências.

Para instrumentalizar as práticas pedagógicas orientadas para os temas transversais, o livro didático pode se constituir em material de apoio importante para os educadores. Porém, deve-se alertar que este é mais uma alternativa importante, mas não a única ferramenta a contribuir para que as temáticas contemporâneas possam se integrar ao ensino. Prioriza-se aqui o cuidado para não utilizá-lo como manual ou receita de planejamento de aula, moldando e uniformizando o currículo escolar de forma homogênea. Sabe-se que o livro pode ser formador e veiculador de ideologias e culturas (D'ÁVILA, 2008), portanto cumpre ao professor desenvolver o olhar que perceba o contraste e as semelhanças entre o conteúdo do livro e a realidade vivida na escola, buscando uma contextualização que tenha significado para o educando, e não uma pedagogia que apresente visão eurocêntrica, perpetuando estereótipos e preconceitos. Neste aspecto, cabe trazer o exemplo do componente curricular Ensino Religioso, que deve ser tratado como uma interpretação que não tente massificar ou homogeneizar as vivências ${ }^{8}$ dos educandos.

A sociedade exige uma educação com mudança de atitude do educador nas situações de ensinoaprendizagem, que considere o período político-social e que viabilize a concretização deste processo por meio de ferramentas de ação capazes de interagir com o educando e com o mundo numa perspectiva de formar cidadãos críticos, através do diálogo e da escuta. Aqui o diálogo é visto não como ferramenta de convencimento, mas sim como forma de respeito às diferenças e possível ampliação e transformação de pontos de vista (BARBOSA, 2002).

Na obra de Paulo Freire A Pedagogia da autonomia (1996), o autor trata desta perspectiva como novas possibilidades, saindo das amarras do preconceito que tantas vezes encontra-se enraizado em práticas cotidianas de sala de aula, como pode ser observado no trecho a seguir:

\begin{abstract}
Viver a abertura respeitosa aos outros e, de quando em vez, de acordo com o momento, tornar a própria prática de abertura ao outro como objeto de reflexão crítica deveria fazer parte da aventura docente. [...] O sujeito que se abre ao mundo e aos outros inaugura com seu gesto a relação dialógica em que se confirma como inquietação e curiosidade, como inconclusão em permanente movimento na História. [...] Como ensinar, como formar sem estar aberto ao contorno geográfico, social, do educando?(FREIRE, 1996, p.86)
\end{abstract}

Hoje nos deparamos com uma complexa relação entre tradição/modernidade e cultura. A cultura, conforme Canclini (2008), abarca o conjunto de processos sociais de significação, ou seja, processos sociais de

\footnotetext{
${ }^{8}$ Hoje é obrigatória a oferta do Ensino Religioso nas escolas do Brasil, fazendo-se necessária a efetivação do que preconizam as leis, ou seja, um Ensino Religioso que respeite a diversidade cultural do Brasil e que seja vedado a qualquer forma de proselitismo, garantindo assim a possibilidade de participação autônoma do cidadão na construção de seus referenciais religiosos, conforme a Lei 9475, que alterou a LDB 9394/96 no art. 33.
} 
produção, circulação e consumo na significação da vida de cada um. Não constitui nenhum tipo de erudição, educação ou informações vastas de grupos de maior ou menor influência social. A cultura é característica plural da comunidade humana, em escala global ou fragmentada. A partir desta perspectiva, podemos falar em hibridismo cultural, que ocorre em espaços de transição e contato onde são misturadas diferentes realidades. A globalização cultural envolve hibridização (STRELOW, 2009).

Na cultura híbrida, ocorrem cruzamentos socioculturais onde o tradicional e o moderno se misturam e, ainda seguindo Canclini (2003), o culto tradicional não é apagado pela industrialização de bens, porém apenas transformado, podendo até ter diminuído seu papel, mas não ser suprimido. Para embasar este pensamento, o autor cita como exemplo o fato de que o trabalho dos indígenas e camponeses ainda mantém o artesanato como função tradicional, atraindo turistas e consumidores urbanos e encontrando nestes bens folclóricos símbolos de distinção. Assim, a homogeneização cultural pretendida pela globalização apagaria os mitos e as crenças e os livros se extinguiriam em prol da midiatização e da informatização de conhecimento. Entretanto, isto não deve acontecer, pois no paradigma da educação no campo, o ensino designa este espaço como ambiente onde se realizem várias dimensões da vida humana e não apenas como espaço de produção de mercadorias. As formulações teóricas da educação no campo preconizam superar o antagonismo entre cidade e campo, sendo visto como complementares (BRASIL, 2007).

\section{Escola do Campo}

A Escola do Campo, conforme o Caderno 2 da SECAD (Secretaria de Educação Continuada, Alfabetização e Diversidade) (BRASIL, 2007), é aquela que tem sua sede no espaço geográfico classificado pelo IBGE como rural, assim como as identificadas com o campo, mesmo tendo em sua sede áreas consideradas urbanas. São assim denominadas quando atendem a população cuja produção social, econômica e cultural está majoritariamente vinculada ao campo. Na década de 1960, a escola do campo passou a ser uma estratégia de política nacional. O governo, por estar preocupado com o número de favelados nas periferias de grandes centros urbanos e para atender interesses de elite brasileira, adotou a educação rural como estratégia de contenção do fluxo migratório do campo para a cidade. Esta visão foi contemplada na Lei de Diretrizes e Bases - LDB de 1961, art. 105, onde estabeleceu que: "os poderes públicos instituirão a ampararão serviços e entidades que mantenham na zona rural escolas capazes de favorecer a adaptação do homem ao meio e ao estímulo de vocações profissionais." Já a LDB publicada em 1971, Lei 5692/71, que foi sancionada durante o regime militar, passou a tratar a educação em regiões rurais a partir de princípios utilitaristas, sendo colocada a serviço da produção agrícola. A seguir, a questão é retomada pela LDB de 1996, onde se reconhecem, em seus artigos 3ำ, 23, 27 e 61, a diversidade sociocultural e o direito à igualdade e à diferença, definindo diretrizes para a educação rural sem rupturas com um projeto global de educação no país. A ideia era de adequação das finalidades, conteúdos e metodologia, com processos próprios de aprendizado específico do campo, permitindo ainda organização escolar própria e calendário escolar adequado ao ciclo agrícola e às condições climáticas.

De acordo com o Instituto de Estudos e Pesquisas Educacionais do Ministério da Educação e Cultura (Inep/MEC), segundo dados de 2006, destacam-se algumas dificuldades relacionadas à escola do campo: precariedade das instalações físicas da maioria das escolas; dificuldade de acesso dos professores e alunos às escolas; falta de atualização das propostas pedagógicas das escolas rurais e currículos inadequados, que privilegiam somente uma visão urbana de educação e desenvolvimento.

Para assegurar que a população rural permaneça no campo, em condições dignas de vida, faz-se necessário uma proposta efetiva em que o acesso à educação e ao conhecimento possa estar vinculado ao contexto da contemporaneidade globalizada e ao sentido de pertencimento local, para que tanto o educador 
quanto os educandos possam perceber-se como cidadãos do mundo, identificando assim a importância de seu papel social.
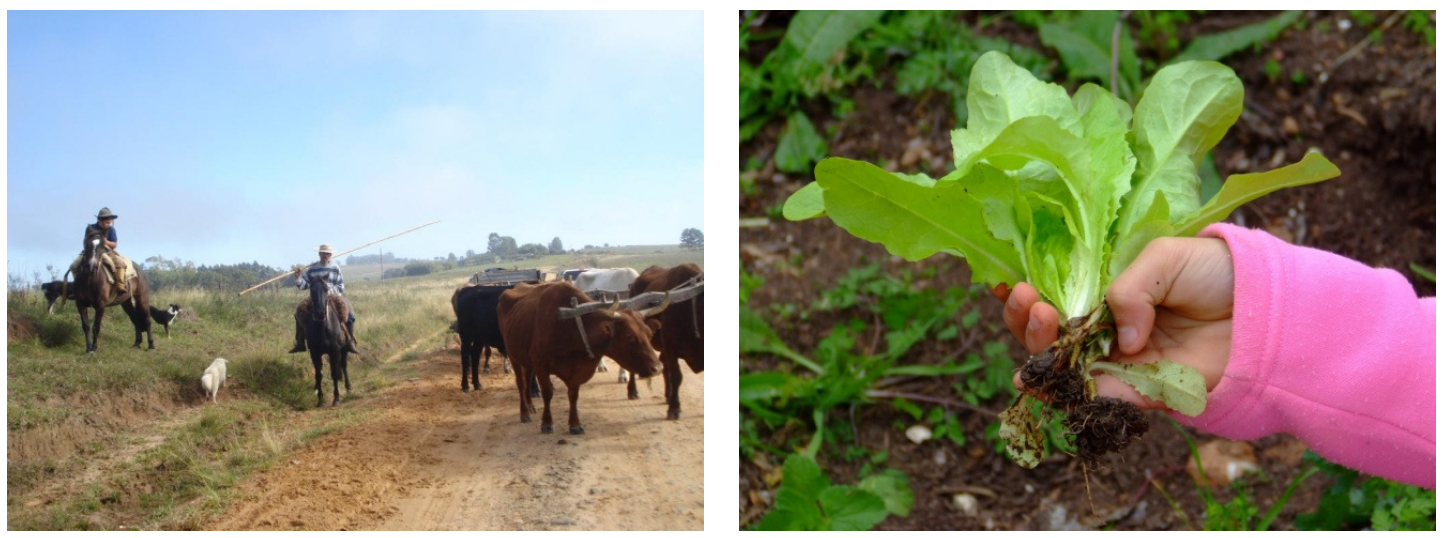

Figuras 1 e 2: Atividades comuns aos educandos e suas famílias.

\section{METODOLOGIA}

A pesquisa mostrada neste artigo é exploratória e de caráter qualitativo, baseada na análise dos questionamentos voltados à temática apontada através de diálogo, observação in locus e entrevistas semiestruturadas com equipe de profissionais da escola e de órgãos públicos envolvidos com atendimento à população rural.

A pesquisa se desenvolveu em maio de 2011 até fevereiro de 2012. Dentro do universo pesquisado, já descrito na seção 1, escolheu-se trabalhar com o terceiro e o quarto anos, pelo fato do ensino ser globalizado ${ }^{9}$ e de se ter unidocência (um único professor responsável por cada turma), fato que, teoricamente, oportuniza a interdisciplinaridade como prática educativa, foco da Especialização em Educação: Interdisciplinaridade e transversalidade. Na escola observada, há pluralidade cultural nos grupos de educandos, os quais se caracterizam por serem afrodescendentes, indígenas, oriundos de assentamentos rurais, filhos de pequenos agricultores, de peões de estâncias e de pequenos proprietários, originários dos municípios de São Gabriel, Cacequi e redondezas.

Durante o período da pesquisa, foram realizadas várias visitas, envolvendo entrevistas também com profissionais da escola dentro da Secretaria de Educação. Acordou-se o Termo de Consentimento Livre e Esclarecido, onde o comprometimento com a ética e com o sigilo de informações particulares é mantido, ficando restrito o uso exclusivo das mesmas para fins científicos ou acadêmicos. A direção da escola colaborou de forma efetiva, mostrando-se extremamente comprometida com o desenvolvimento da pesquisa e disponibilizando informações, materiais, documentos, livro ata de ocorrência e espaços da escola de forma integral.

\footnotetext{
${ }^{9}$ Nessa metodologia globalizada, as disciplinas se integram e os conteúdos não são fragmentados, de acordo com a prática escolhida pelo educador. Disponível em:< http://www.preve.com.br/base.asp?pag=metodo.htm>Acesso em: 02 jan.2012. 


\section{ANÁLISE E DISCUSSÃO DOS DADOS}

\section{A aplicação das propostas do MEC na escola}

O município aderiu a dois programas específicos para escolas rurais através da Secretaria Municipal de Educação - SEME, dentro do PAR - Plano de Ação Articulada, que é o caso da Escola Ativa e do Agrinho ${ }^{10}$.

A Escola Ativa oferece capacitação mensal a todas as escolas do campo no município que possuem classes multisseriadas ou não, nas séries iniciais do primeiro ao quinto ano.

O programa Agrinho também tem prioridade pautada em oferecer aos educadores alternativas metodológicas, porém com um olhar direcionado à abordagem dos Temas Transversais (Meio ambiente, Saúde, Trabalho e consumo, Ética, Pluralidade cultural e Educação sexual).

Estes programas, mesmo ainda sendo pontuais e pouco explorados, possibilitam aos educadores da escola estudada acesso a novas práticas pedagógicas orientadas para problemáticas específicas das práticas de escolas de campo. Uma das dificuldades encontradas para contemplar o acesso aos educadores de forma continuada, é que a escola em estudo se faz sempre presente nos encontros da escola ativa, porém nem sempre pelo mesmo educador, devido há indisponibilidade de substitutos para suas turmas.

\section{A visão histórica dos componentes curriculares da escola}

Ao observar a forma como a Pluralidade Cultural é contemplada nos componentes curriculares do planejamento diário de aula, ressaltam-se algumas peculiaridades para reflexão.

A abordagem dada pela disciplina de História/Estudos Sociais aos educandos se baseia em uma perspectiva europeia, cuja metodologia praticada se utiliza principalmente do uso de recursos complementares que são o giz e a lousa, na qual são registrados os conteúdos que tem como referencial o caderno do plano de aula da professora. O livro didático não é utilizado e os PCNs não são consultados.

Tratar de história é de fundamental relevância cultural na construção crítica do cidadão na medida em que o tema nos desafia a refletir sobre qual importância da representação do passado na nossa contemporaneidade. Sabe-se que as experiências humanas produzem sentido na medida em que dizem respeito à nossa inserção na comunidade, possibilitando a singular condição de pertencimento ao mundo. Aqui importa a forma como o conteúdo é abordado, que prática educativa é utilizada, como é percebido pelos educandos, se está sendo somente mera reprodução de conhecimento ou se permite uma transposição para uma linguagem coerente, permitindo uma reflexão acerca de sua importância em nossa vida e nosso mundo. Dessa forma, Arendt (1995, p. 68) explica que "Todo pensamento deriva da experiência, mas nenhuma experiência produz significados ou mesmo coerência sem passar pelas operações de imaginação e pensamento".

Ao analisar o planejamento de aulas, referente ao conteúdo sobre o Brasil colônia, constata-se um exemplo de preconceito quando os índios são mostrados como figuras simbólicas primitivas, domesticáveis ou até selvagens, catequizados pelos jesuítas, que habitavam ocas e eram dominados pelo chefe da tribo, chamado de Pajé. Atrelada a essa concepção, não há no

\footnotetext{
${ }^{10}$ Programa de responsabilidade social do sistema FAEP e seus parceiros. Disponível em: $<$ <ttp://www.agrinho.com.br/beta/area_publica/controles/ScriptPublico.php > Acesso em:02 jan. 2012. 
currículo qualquer menção ao índio Sepé Tiaraju, que se trata de uma referência histórica para o município de São Gabriel.

A história do município remonta a 1750, com o surgimento das primeiras estâncias jesuíticas dos Sete Povos das Missões, onde religiosos da Companhia de Jesus catequizavam militarmente os índios guaranis. Pelo tratado de Madri, assinado naquele ano, o que constituía o território do atual município, na região oeste do RS, passou a pertencer a Portugal, pois até então era da Espanha. Mas as disputas internas de fronteiras entre as coroas ibéricas, os índios e os habitantes da comunidade local se seguiram até a Batalha de Caiboaté, em 1857, quando morreram o líder guarani Sepé Tiaraju e milhares de índios. Entretanto, em 2 de novembro de 1800, o naturalista espanhol Félix de Azara fundou, junto ao Cerro do Batovi, uma povoação, dando o nome de São Gabriel, mas a demarcação definitiva só viria com o acordo sobre os limites da fronteira, assinado em 1819, em Montevidéu, que incorporava São Gabriel ao Brasil de caráter definitivo (PESAVENTO, 2002).

Ignorar este mito é negar a existência de um símbolo presente na história regional, é desvincular-se de questões mundiais acerca da luta pela territorialidade de nosso município, região e país, em prol do direito de propriedade e na recusa pela invasão e derrota.

O mito Sepé Tiaraju é um símbolo, pois ao ecoar as palavras "Esta terra tem dono", frase a ele atribuída pela memória coletiva, reafirma que anterior à invasão europeia havia uma cultura e um sentido de pertencimento que clamava pelo direito da comunidade local viver no lugar em que nasceu. Cumpre, pois que no espaço escolar se façam abordagens no sentido de mostrar o pioneirismo dos povos indígenas na comunidade em que se vive, reconhecendo-os historicamente a fim de revisar inúmeras concepções sobre o tema que permitam reconstituir informações que possam vir a despertar curiosidade e sentido de pertencimento.

Na perspectiva freireana, a história contada a partir de uma visão europeia e uma prática reacionária elitista é um retrocesso à prática progressista. Neste sentido, questiona Morin (2004): “Como pensar a sustentabilidade do desenvolvimento da sociedade brasileira, reproduzindo os ícones de um processo civilizatório, cujas conquistas erigiram-se na força do afogamento das pequenas civilizações, das nações, terras, culturas e saberes indígenas?" (MORIN, 2004, p. 16)

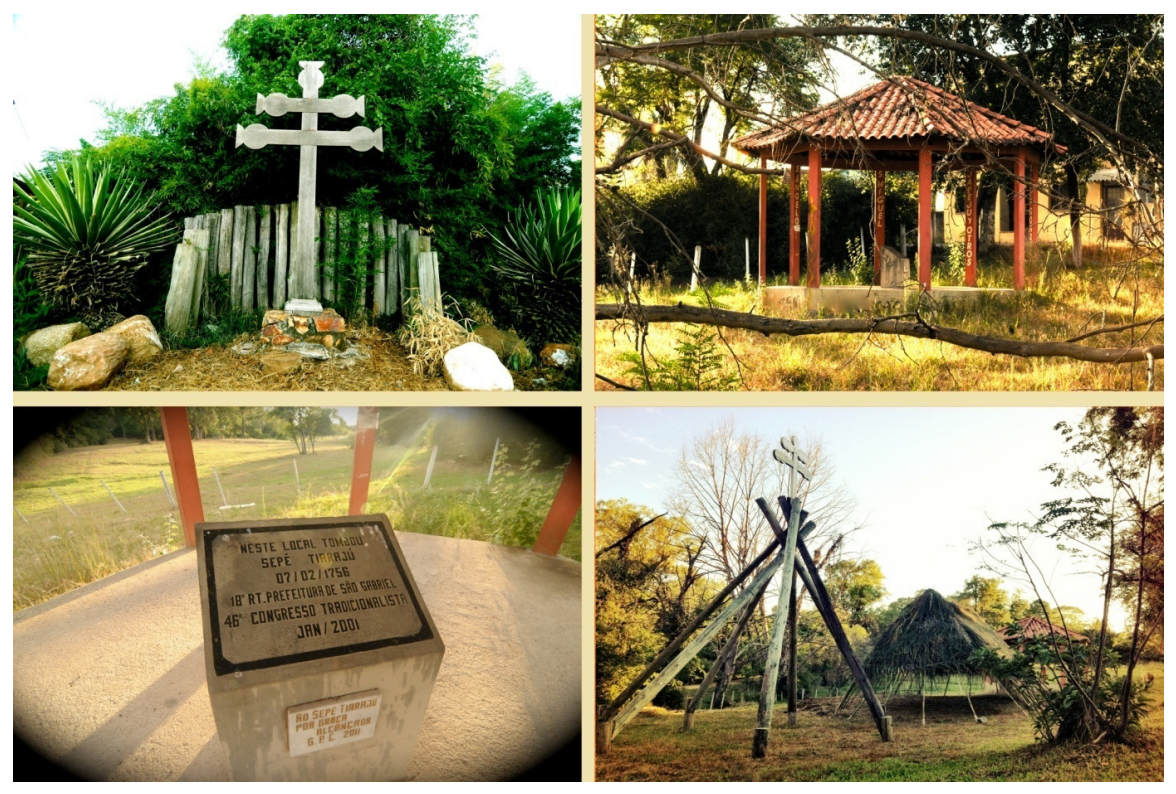

Figuras 3, 4, 5 e 6: Monumentos que simbolizam a representatividade de Sepé Tiaraju no município de São Gabriel. 
Partindo desta questão e relacionando à Educação não formal, ao se tratar da temática sobre questões indígenas nas escolas do município de São Gabriel, deve-se discorrer sobre o cidadão indígena e seus direitos, através da reconstituição histórica real. É necessário resgatar uma dívida nacional para com as comunidades indígenas que viviam no pampa rio-grandense. Também é preciso tratar com veracidade os fatos formais e informais, trazendo o processo de violência física e cultural efetivado pela colonização, além dos trabalhos forçados como mão de obra produtiva ou ainda, reprodutiva (abuso sexual de mulheres índias) em prol da construção nacional (SOUZA, 2004).

\section{A Religião e as datas comemorativas nos componentes curriculares da escola}

Percebe-se que a religião proposta nesta escola é a apostólica católica romana, pois a Campanha da Fraternidade é bastante evidenciada. Nos registros e falas, fica evidente a importância da evangelização. Além da Quaresma, Páscoa, Corpus Christi, Finados e Natal, são trabalhados no Ensino religioso temas como Família, Dia da criança e Meio ambiente, associados a valores e atitudes como amizade e solidariedade.

$\mathrm{Na}$ escola analisada, o calendário escolar está totalmente preenchido com datas comemorativas, tendo como critério inicial de elaboração o Carnaval. Estas são temáticas geralmente ligadas à cultura nacional. A celebração de eventos pode valorizar a diversidade cultural, seja através de músicas, danças, rituais, valores, crenças e trajetórias históricas. Estas comemorações, porém, não devem acontecer apenas no dia agendado no calendário letivo, de forma estanque, pois assim como a educação é um processo, estas datas representam a culminância dos temas, sendo pertinente estarem presentes no planejamento dos educadores.

Datas comemorativas como Dia do Índio, Dia do Meio Ambiente, Dia da Criança, Dia das Mães, Dia dos Pais, Dia da Consciência negra, festas e datas religiosas, podem ser trabalhadas de forma transversal, desde que inseridos nos componentes curriculares durante todo ano, de forma significativa, de acordo com o plano de aula. A comemoração destes eventos colabora ainda na educação da comunidade escolar; no desenvolvimento do respeito e ao apreço pelas manifestações artísticas e culturais de vários grupos; na formação cidadã do educando, consciente de seus direitos e deveres e, também, na construção de laços de solidariedade entre a comunidade escolar. Na escola pesquisada, as datas comemorativas não se restringem a um único dia apenas, sendo conectadas a um plano mais extenso, através de apresentação de teatro, mostra pedagógica, festas envolvendo as famílias e outras atividades, entretanto, não são desenvolvidas nos componentes curriculares de forma interdisciplinar.

\section{A negação das diferenças no espaço escolar}

Em relação ao tema preconceito, a educadora se diz isenta. Isentar-se acarreta consequências. É a negação de atitude, repassando a solução do problema ao plano espiritual. A passividade ou falta de análise, autocrítica, na perspectiva freireana caracteriza a ação de um profissional alienado. Quanto ao preconceito de gênero, foi relatado casos de homossexualismo na escola, entretanto existe uma discriminação velada dos educadores, pois ao perceberem os alunos que discriminam, sua postura é passiva, de suposta neutralidade, novamente induzindo a negação do problema, o que se configura numa forma de violência entre os educandos, o Bullying ${ }^{11}$.

\footnotetext{
${ }^{11}$ Bullying é um termo utilizado para descrever atos de violência física ou emocional, intencionais e repetidos, praticados por um indivíduo (do inglês bully, tiranete ou valentão) ou grupo de indivíduos causando dor, angústia e sofrimento, sendo executadas dentro de uma relação desigual de poder, sendo a escola o principal cenário onde esta prática prevalece. 


\section{O suporte oferecido às famílias dos alunos}

A Escola do Campo, onde foi desenvolvida a pesquisa, encontra-se dentro de uma área cedida pelo INCRA, na qual existem 55 lotes de famílias assentadas, desde 1996, contando com uma população de 166 pessoas, sendo que 39 dos educandos são filhos destes assentados. O assentamento é formado por extrabalhadores rurais, arrendatários, boias-frias e meeiros que vieram de várias localidades do próprio estado. A equipe do Escritório Municipal da Associação Rio-grandense de Empreendimentos e Assistência Técnica e Extensão Rural - EMATER/RS-ASCAR - de São Gabriel coordena ações e metas para o plano de reestruturação e desenvolvimento deste assentamento. $O$ trabalho é desenvolvido por este órgão através de convênio com o INCRA e, conforme documentação apresentada e diálogo com a extensionista ${ }^{12}$ responsável e equipe técnica, este se dá através de visitas individuais nas casas das famílias e também na escola. A formação superior da extensionista é Pedagogia, atuando através de projetos que visam o bem-estar social das famílias assentadas, a partir da coleta e disponibilização de informações que definem as necessidades e anseios da comunidade.

Além desta profissional, atua também um técnico agrícola, que faz assistência desde condições do solo e do plantio até a colheita, incluindo orientações na criação de gado. As palestras e/ou oficinas são mensalmente oferecidas e acontecem no espaço escolar, abertas a toda comunidade local. Alguns temas desenvolvidos durante este ano foram: "Implantação de hortas - manejo e plantio", "Produção de alfafa", "Coleta de água da chuva" e oficinas de artesanatos. Atrelada a esta proposta, a secretaria de Educação do município busca também parcerias com Universidades, COPTEC (Cooperativa de Prestação de Serviços Técnicos em áreas de Reforma Agrária) e outras redes de apoio, como Secretaria de Saúde, Secretaria de Assistência Social e Secretaria do Meio Ambiente.

Importante ressaltar que, no diálogo com diretora e supervisora, houve relatos de que durante alguns anos a escola sofria frequentemente arrombamentos, às vezes seguidos de roubo (TV, aparelhos de DVD, ventiladores, merenda escolar), configurando a prática de atos de vandalismo (quebra de vidros das salas de aula, corte da cerca de arame que fecha a escola, abertura de torneiras, depredação de mudas plantadas pelos próprios alunos com orientação de educador, entre outros fatos). Diante deste cenário, a direção teve iniciativa de chamar todos educandos e seus familiares a fim de entrarem em acordo e atenuarem estas ocorrências, embora a maioria dos atos tenham sido a apenas alguns assentados. Foi então resolvida questão por meio da permissão aos alunos para entrarem na escola nos finais de semana, ocupando o espaço aberto e a quadra de esportes. Como resultado desta iniciativa, até o final do ano letivo de 2011 foi registrado apenas um arrombamento seguido de roubo da merenda estocada.

\footnotetext{
${ }^{12}$ O papel da Assistência Técnica e Extensão Rural- extensionista (ATER) insere-se na perspectiva de construir processos que promovam o desenvolvimento local de forma sustentável (assumindo aqui as múltiplas dimensões da sustentabilidade: o social, o ambiental, o econômico, o político, o ético e o cultural), em sintonia com os referenciais teóricos e metodológicos da Instituição. Esse esforço articula-se com uma rede ampla de parceiros, que envolvem instituições de pesquisa e ensino, organizações e movimentos sociais, conselhos, fóruns, comitês e várias outras instâncias de representação e construção coletiva, sejam de âmbito municipal, regional e estadual.
} 


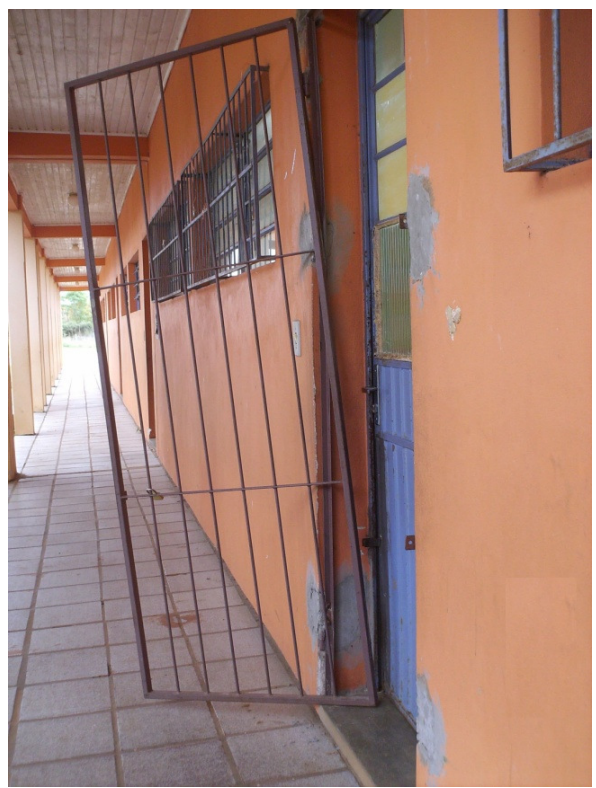

Figura 8: ato de vandalismo que demonstra conflitos e expõe situação de vulnerabilidade da escola.

A Educação não formal se reforça nestas atitudes ao estabelecer-se o diálogo e o interesse em resolver problema local. Percebe-se que, muito além do suporte técnico oferecido à comunidade dos educandos em estudo, os mesmos necessitam ser reconhecidos na perspectiva da cultura de origem pelas pessoas que trabalham nessa escola (educadores, funcionários e direção) que, concordando com Boas (2007), somente a partir da percepção e da valorização de todas as culturas ali presentes com histórias próprias de cada grupo, iniciará a construção de um alicerce norteador que oriente o enfrentamento de questões complexas quanto à aceitação do outro, na medida em que olhar com alteridade significará uma forma de acolhimento e pertencimento.

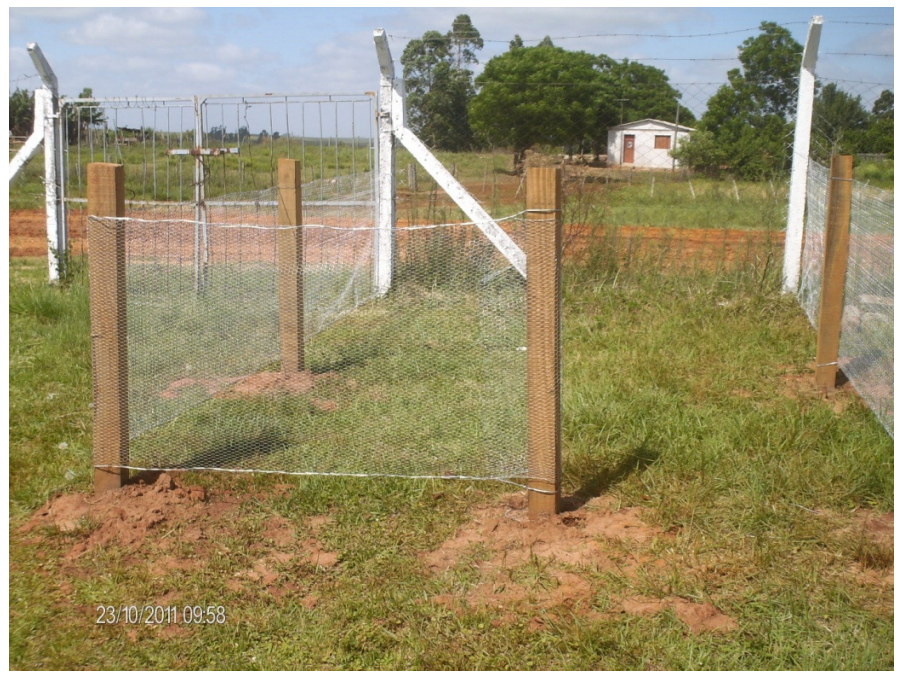

Figura 7: Visão a partir do interior da escola do portão de entrada e da cerca que entorna a mesma. 


\section{A análise documental do Regimento Escolar: teoria e prática}

Com relação à análise documental, destacam-se três itens que compõem o Regimento Escolar vigente na Escola. Para Paulo Freire (2004, p. 60) o que interessa "é saber se a escola trai ou confirma o regimento que está escrito." Desse modo, a análise da prática, que vai confirmar ou não o texto desse documento, levará também "às coisas que estavam escondidas no texto, e que no fundo é a posição ideológica, por exemplo, de quem fez o texto, de quem escreveu o regimento" (FREIRE, 2004, p.60).

Os itens analisados no Regimento também constam nos Princípios Básicos para a Escola do Campo. Conforme os princípios, aos educandos se reserva o direito de acesso aos recursos tecnológicos, ao acervo bibliográfico contextualizado e qualificado e ao resgate e valorização do saber local através do currículo. Infelizmente, na escola pesquisada, a sala de informática não está funcionando. $O$ espaço e os equipamentos estão ali, porém os computadores não funcionam. A sala reservada ao acervo bibliográfico é coerente às necessidades da escola quanto ao espaço, mas os livros são escassos e não despertam atenção dos educandos, talvez pelas temáticas, pelo aspecto visual ou pela falta de atualização de obras de literatura qualificadas e adequadas (tanto a literatura clássica infanto-juvenil, quanto o acervo de livros científicos). Este cenário vem a confontar às perspectivas de educação de qualidade para todos, que a LDB prioriza e contradizer sua inserção no mercado global de informações imediatas.

\section{A participação/organização das famílias}

No decorrer das observações e diálogos em sala de aula, percebe-se o desenvolvimento de atividades domésticas realizadas pelas crianças camponesas nas famílias de meeiros e assalariados, como forma de complementar a renda e de educar os filhos para o trabalho (Educação Informal), situando esta prática como uma tradição cultural ou um modo de vida específico que as crianças gostam de compartilhar.

Tal prática se concretiza na fala de alguns educadores que dizem que o filho ajuda na lida do campo, que sai com seu pai nas atividades de campeiragem ${ }^{13}$, ou que a filha ajuda na ordenha das vacas, na tosquia e no cultivo da horta. Independentemente de serem meninos ou meninas todos participam, quando não estão na aula, de alguma tarefa junto aos seus pais (dentro de casa e no campo). Essas atividades estão associadas à cultura do campo. Pela presença de algumas mães vendendo produtos de suas hortas em determinados dias da semana na escola, nota-se que esta iniciativa é uma tentativa de inserção no mercado de trabalho e também um meio de garantir seu próprio sustento. Além de que, dentro do espaço escolar, passa a ser uma forma de socialização e aceitação. Ressalta-se, portanto, que o trabalho apresenta um caráter não somente profissional, mas também uma atividade essencial na sua vida familiar rural. 0 aprendizado e a vivência destes valores da cultura rural até aqui relatados constroem a educação doméstica destas famílias.

Esta Escola, enquanto espaço de construção de conhecimentos, está atrelada à proposta de valorizar e redirecionar esta bagagem cultural a fim de aprimorá-la através de uma ressocialização em consonância com a comunidade. O que se observa realmente é que esta cultura local, atrelada ao imaginário popular do universo rural se faz presente no ambiente pesquisado, mas que o processo deve ter sofrido influências externas, já que a aculturação é um fenômeno universal (CANCLINI, 2008).

A valorização do estudo aos filhos, por parte dos pais, é evidenciada na medida em que se constata a presença destes em reuniões, atividades comemorativas e outras situações que promovam o encontro das

\footnotetext{
${ }^{13}$ Ato de campeirear ou fazer serviços no campo (CORRÊA et al., 1964). 
famílias na escola, conforme observação e falas da direção. Foi relatado que a maioria dos pais não exige o estudo em casa, não reservando horas para ele, e também não ajuda os filhos nas tarefas, ou porque trabalham ou porque não possuem condições culturais para auxiliar seus filhos ${ }^{14}$. Através de observações e relatos de educadores percebe-se que as crianças possuem celulares, usam bonés e quase todas têm televisão em casa, embora muitas delas não tenham água potável nem saneamento básico, comprometendo a própria sobrevivência humana. O que se observa também, é que alguns valores sofreram influência da sociedade urbana enquanto, ao mesmo tempo, outros se mantiveram associados tradicionalmente à cultura rural, manifestando um processo de hibridismo cultural (CANCLINI, 2008).

A condição para uma adequada utilização da água, muitas vezes depende do acesso e do controle/gerenciamento sobre os recursos naturais. Portanto, o acesso à água, saneamento, energia, terra e biodiversidade, que são fundamentais para nossa própria subsistência, deveriam ser prioritários nas políticas de desenvolvimento social, articulando a promoção da equidade ${ }^{15}$. Frente a esta situação, destaca-se que:

Quando se analisa uma situação concreta específica (uma comunidade humana particular nas suas relações com o seu meio ambiente), a questão das relações entre as dinâmicas locais e outras dinâmicas mais globais e amplas coloca-se como um assunto fundamental. Em particular, tratando-se dos desdobramentos sociais e ambientais da globalização econômica, em situações concretas - seus efeitos locais sobre a "sustentabilidade social" e a "sustentabilidade natural"deve-se levar em conta a complexidade das relações que as mudanças locais mantêm com fatores e ditames externas de abrangência mais global. Não se pode desvincular a realidade dos determinantes globais e nem reduzir o que está acontecendo localmente a consequências mecânicas dos fatores externos (ROCHA, 2011).

Ainda em 2011, escola estudada teve nova direção a partir de abril, quando se observou que uma das prioridades da equipe diretiva foi trazer a comunidade local para dentro da escola, proporcionando mostras pedagógicas, apresentações nas datas comemorativas e reuniões de pais, entre outras estratégias.

Como resultado desta proposta, a escola tornou-se, no decorrer de 2011, o espaço mais utilizado para troca de vivências, tanto pela parte dos educandos como de toda comunidade escolar.

\section{CONSIDERAÇÕES FINAIS}

Longe de esgotar a discussão, espera-se que este trabalho, contribua para a implantação ou aprofundamento de algumas políticas públicas ou ações que promovam oportunidades de acesso e de inclusão social aos cidadãos brasileiros que vivem no campo, permitindo um crescimento sustentável e ambientalmente mais justo, solidário e menos desigual. ${ }^{16}$

Percebe-se que em todos os momentos da pesquisa os Temas Transversais aparecem na caracterização situacional analisada, mas alguns - principalmente a Pluralidade Cultural, não estão sendo bem tratados pela escola (no caso da religião e do preconceito). Os Temas Transversais são extremamente importantes e necessitam ser abordados de forma mais abrangente e eficaz no cotidiano escolar, porém,

\footnotetext{
${ }^{14}$ Há ainda informações de vários casos de problemas de alcoolismo nas famílias.

${ }^{15}$ A Secretaria Municipal de Educação (SEME) implementou projetos nas Escolas do Campo, cujo diagnóstico parcial do projeto-piloto - “Lixo Rural/2011” - comprovam a problemática sócio ambiental e cultural a qual esta parcela da população está submetida. Outro projeto que se originou do piloto é uma parceria entre a SEME e a Universidade Federal do Pampa - UNIPAMPA, que é “Caracterização Higiênico-Sanitária e Educação Ambiental nas escolas de zona rural de São Gabriel/RS". A proposta tem por objetivo caracterizar e propor melhorias relacionadas ao fornecimento da água de boa qualidade a comunidade escolar, além de envolver os educandos em palestras e oficinas relacionadas a temas relevantes da educação ambiental, incluindo o cuidado com o descarte produzido. 0 projeto piloto teve início em novembro de 2011 em uma escola Polo, devendo se estender às outras conforme disponibilidades das parceiras envolvidas.

${ }^{16} \mathrm{O}$ estudo, por ter utilizado uma mostra pequena e ter sido trabalhado em contexto bem específico, não sugere generalizações em suas análises.

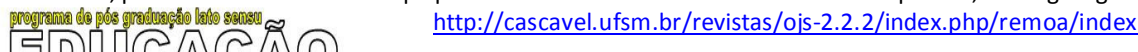


muitas vezes, não são valorizados nem trabalhados na escola, sendo desenvolvidos de forma ineficiente. Não se trata de atribuir juízo de valor, mas sim ressaltar a importância da utilização de uma abordagem que valorize as diferentes culturas ali presentes, independentes de credo ou etnias e que desperte o senso crítico nestes educandos, respeitando-os e motivando-os para a vida e o trabalho.

Mesmo considerando ser a escola um ambiente de intercâmbio cultural muito amplo e que deve ter suas portas abertas para todos, é necessário considerar as contradições do sistema educacional brasileiro, quando analisamos em suas práticas algumas formas de tentar uniformizar, homogeneizar o ensino, desconsiderando possíveis especificidades e vulnerabilidades que possam comprometer a inclusão social e valorização cultural do educando.

$\mathrm{Na}$ análise dos relatos sobre os Temas transversais - a Pluralidade Cultural, especificamente no planejamento de aula, está sendo abordada como cultura idealizada, mítica, elitizada, não aproximando as crianças de alguns temas que deveriam, pela herança cultural, aproximar, incorporar, dar sentido de pertencimento aos seus/nossos antecedentes. Um exemplo desta afirmação traz o questionamento quanto à presença da figura do negro na caracterização histórica do município. O tratamento à questão do índio está marginalizando seus descendentes, totalmente desvinculado da vivência daquele descendente indígena que se faz presente nas aulas dadas. O gaúcho também é elitizado, não sendo popularizado na escola (nem na cidade), pois apesar de forte tradicionalismo vigente no município, no desfile da Semana Farroupilha poucos afrodescendentes vimos desfilando, sem falar em algum descendente indígena ou assentado. Na escola, a história vem tratando mitos como verdades, não apresentando linearidade nem coerência entre o ontem e hoje. Isto é consequência de políticas públicas estabelecidas que não analisam os vários contextos, que não fazem distinção entre os conceitos de ideologia e idealização/mitificação e que não conhecem as plurais culturas da sociedade a qual estamos inseridos.

Ao trabalhar no setor pedagógico da SEME como pedagoga, pude identificar que a educação hoje é priorizada no município, através da busca de um novo olhar pelo setor de política pública responsável, que vem desenvolvendo uma gestão amparada em ações e estratégias voltadas a uma escola de qualidade. Esta proposta é enfatizada nas Escolas do Campo, seja na construção e execução de projetos, na capacitação profissional ou pelo suporte pedagógico oferecido. Porém, esses esforços esbarram, na maioria das vezes, em escolas com educação tradicional e uma cultura talvez não tão comprometida com a ética dos direitos humanos, expondo sua fragilidade.

Explicações para este panorama de discrepância entre o discurso e a prática metodológica encontrada podem ser inúmeras. Entre estas, destaca-se deficiências na formação de professores, ausência de material didático adequado, cultura escolar resistente às mudanças curriculares, renovações de práticas docentes e preconceitos enraizados historicamente, entre muitas outras. A questão dos assentados está atrelada aos indígenas, no que tange ao direito de propriedade da terra, onde os ruralistas e estancieiros, proprietários de grandes extensões de terra, apropriaram-se da frase "Esta Terra tem dono" e distorceram seu contexto, usando o lema de autoria atribuída ao índio guarani Sepé Tiaraju, contra a ocupação do MST, discriminando-os pelo fato de serem vistos como invasores de terras.

Entre especificidades da zona rural, acrescenta-se a escassa disponibilidade do professor do currículo de participar de capacitações na cidade, pois precisa de substituto tempo integral em virtude da dificuldade de acesso, já que os horários de entrada e saída são limitados, além das interferências climáticas, que interrompem a continuidade das aulas.

Percebe-se que a cerca que envolve a Escola ainda é frágil, sujeita a rupturas ou cortes. Na tentativa de atenuar essa fragilidade deve-se reforçar o sentimento de pertença destes educandos para com a instituição. E cumpre a ela, através do desenvolvimento de práticas pedagógicas em parceria com uma Educação não formal, adequar-se às necessidades da comunidade, proporcionando a interação do contexto educacional com o social, possibilitando então uma inclusão legítima. 
Em outras palavras, ousaria dizer que somente ao buscar entender as relações de poder entre as culturas (escolar - formal e identidades culturais dos estudantes), poderá se alcançar na escola um espaço de diálogo entre estas diferenças culturais, por meio da promoção de debates, projetos e outras atividades Educação não formal, oportunizando a discussão entre as diferentes vozes culturais, dentro e fora da escola. Para tanto, cabe aos educadores abrirem-se às mudanças da contemporaneidade que vivemos, reconhecendo-se como principais fontes de formar sujeitos críticos e capazes de transformação social, desconstruindo aulas que, muitas vezes, estão petrificadas através dos tempos, apenas reproduzindo um conhecimento repetido todos os dias, como uma oração, sem qualquer análise ou reflexão. Esse é o primeiro passo, o restante será consequência natural da maneira com que a escola conduz pricipalmente duas questões: se há comprometimento e participação no processo democrático para concretizar uma educação de qualidade e se as ações efetivadas realmente vem de encontro às necessidades daquela comunidade escolar.

\section{REFERÊNCIAS BIBLIOGRÁFICAS}

ARENDT, Hanna. Entre o passado e o futuro. São Paulo: Perspectiva, 1978.

. A Vida do Espírito. Trad. Antonio Abranches e Helena Martins. Rio de Janeiro: Relume Dumara, 1995.

BARBOSA, Laura M. S. PCN: Parâmetros Curriculares Nacionais: temas transversais. v. 2. Curitiba: Bella Escola, 2002.

BAUMAN, Zygmunt. Amor líquido: sobre a fragilidade das relações humanas. Rio de Janeiro: Jorge Zahar Ed., 2004. BOAS, Franz. Antropologia Cultural. 4 ed. Rio de Janeiro: Jorge Zahar , 2007.

BRASIL. Lei 11645, de 10 de Março de 2008. Altera a Lei $n^{\circ}$ 9.394, de 20 de dezembro de 1996, modificada pela Lei $n^{\circ} 10.639$, de 09 de janeiro de 2003, que estabelece as diretrizes e bases da educação nacional, para incluir no currículo oficial da rede de ensino a obrigatoriedade da temática "História e Cultura Afro-Brasileira e Indígena". Disponível em: <http://www.planalto.gov.br/ccivil_03/_ato2007-2010/2008/lei/l11645.htm> Acesso em: 10 fev.2012.

. Lei 10.639, de 09 de janeiro de 2003. Altera a Lei no 9.394, de 20 de dezembro de 1996, que estabelece as diretrizes e bases da educação nacional, para incluir no currículo oficial da Rede de Ensino a obrigatoriedade da temática "História e Cultura Afro-Brasileira", e dá outras providências. Disponível em: <http://www.planalto.gov.br/ccivil_03/leis/2003/L10.639.htm> Acesso em: 10 fev.2012.

. Lei 9.475 de 22 de julho de 1997. Dá nova redação ao art. 33 da Lei de Diretrizes e Bases da Educação Nacional. Disponível em: <http://www.planalto.gov.br/ccivil_03/leis/L9475.htm> Acesso em: 10 jan. 2012.

. Lei n. 9394, de 20 de dezembro de 1996. Estabelece as diretrizes e bases da educação nacional. Disponível em: <http://www.planalto.gov.br/ccivil_03/Leis/L9394.htm> Acesso em: 10 jan. 2012.

. Ministério da Educação. Educação do campo: diferenças mudando paradigmas. Secretaria de Educação Continuada, Alfabetização e Diversidade (Secad/MEC). Brasília: MEC, 2007. Disponível em:< http://portal.mec.gov.br/secad/arquivos/pdf/educacaocampo.pdf> Acesso em:10 fev.2012.

. Ministério da Educação. Parâmetros curriculares nacionais: Pluralidade Cultural: Orientação sexual. Ministério da Educação. Secretaria da Educação Fundamental. 3. ed. - Brasília: A Secretaria, 2001.

. Ministério da Educação. Parâmetros curriculares nacionais: introdução aos parâmetros curriculares nacionais / Secretaria de Educação Fundamental. - Brasília: MEC/SEF, 1997. Disponível em: $<$ <ttp://portal.mec.gov.br/seb/arquivos/pdf/livro01.pdf>. Acesso em: 18 jul. 2011.

1996. Ministério da Educação. Parâmetros Curriculares Nacionais. Temas Transversais. Brasília: MEC/SEEC,

. Senado Federal. Constituição Federal da República do Brasil. Brasília, Senado Federal: Centro gráfico, 1988.

BRUM, Ceres Karam. Sepé Tiaraju missioneiro: um mito gaúcho. Santa Maria: Pallotti, 2006.

CANCLINI, Nestor Garcia. A globalização imaginada. São Paulo: lluminuras, 2003. 
Culturas Híbridas: estratégias para Entrar e Sair da Modernidade. 4. ed. São Paulo: Editora Universidade de São Paulo, 2008.

CORREA, Romaguera; CORUJA, Antonio A. P.; MORAES, Luiz Carlos de, CALLAGE, Roque. Vocabulário SulRio-Grandense: termos e expressões de Quatro Dicionários Rio-Grandenses; uma coletânea de vocábulos da Região Sul; usos modernos e tradicionais de um linguajar vivo. Porto Alegre: Globo, 1964.

D'ÁVILA, Cristina. Decifra-me ou te devorarei: o que pode o professor frente ao livro didático? Salvador: EDUNEB; EDUFBA, 2008.

EAGLETON, Terry. A idéia de cultura. São Paulo: Ed. UNESP, 2005.

FREIRE, Paulo. Pedagogia do oprimido. Rio de Janeiro: Paz e Terra, 2005.

. Pedagogia da tolerância. Organizado por Ana Maria Araújo Freire. São Paulo: UNESP, 2004.

. Pedagogia da autonomia. Saberes necessários à prática educativa. São Paulo: Paz e Terra, 1996.

. Educação e mudança. 24 ed. Rio de Janeiro: Paz e Terra, 1979.

FUNDAÇÃO DE ECONOMIA E ESTATÍSTICA. Estimativa da população por município e situação de domicílio, Rio Grande do Sul, 2010. Disponível em: <http://www.fee.tche.br/sitefee/pt/content/estatisticas/pg_populacao_tabela_03.php?ano=2010\&letra=S\&nome $=$ S\%E3o+Gabriel $>$ Acesso em: 02 fev. 2012.

LARAIA, Roque de Barros. Cultura: um conceito antropológico. 22 ed. Rio de Janeiro: Jorge Zahar, 2008.

MELATTI, Júlio César. Índios do Brasil. São Paulo, Ed. Da Universidade de São Paulo, 2007.

MORIN, Edgar. Saberes Globais e Saberes Locais, o olhar interdisciplinar: Ideias sustentáveis. Rio de Janeiro: Garamond, 2004.

PESAVENTO, Sandra Jatahy. História do Rio Grande do Sul. 9 ed. Porto Alegre: Mercado Aberto, 2002.

PETRINI, João Carlos. Pós-modernidade e família: um itinerário de compreensão. Bauru: SP. EDUSC, 2003.

ROCHA, Jefferson Marçal da. Sustentabilidade em questão: Economia, sociedade e meio ambiente. Jundiaí: Paco Editorial, 2011.

SANTOS, Boaventura S. A crítica da razão indolente - Contra o desperdício da experiência. São Paulo: Cortez, 2000.

SANTOS, Milton. Por uma outra globalização: do pensamento único à consciência universal. 10. ed. Rio de Janeiro: Record, 2003.

SILVA, Ezequiel Theodoro da. Conhecimento e cidadania. Quando a leitura se impõe como mais necessária ainda! In: LOMBARDI, José Claudinei (Org.). Globalização, pós-modernidade e educação: História, filosofia e tema transversais. São Paulo: Autores Associados: HISTERDER: Caçador, SC, UNC, 2009. (Coleção educação contemporânea)

SILVA, Gilberto Ferreira da; PENNA, Rejane; CARNEIRO, Luiz Carlos da Cunha (Orgs.). RS índio: cartografias sobre a produção do conhecimento [recurso eletrônico]. Porto Alegre: EDIPUCRS, 2009. 300 p. Disponível em: <http://www.pucrs.br/orgaos/edipucrs/ >. Acesso em 15 dez. 2011.

SOUZA, José Otávio Catafesto. Mobilização indígena, direitos originários e cidadania tutelada no sul do Brasil depois de 1988. In: FONSECA, Cláudia; TERTO JR., Veriano; ALVES, Caleb Farias (Orgs.). Antropologia, diversidade e direitos humanos: diálogos interdisciplinares. Porto Alegre: UFRGS, 2004.

STRELOW, Aline. Pampa e Cultura: o hibridismo cultural no Rio Grande do Sul. Revista Elementa. Comunicação e Cultura. Sorocaba, v.1, n.2, jul/dez 2009. Disponível em: <http://comunicacaoecultura.uniso.br/elementa/v1_n2_02.pdf> Acesso em: 20 dez 2011.

ZITKOSKI, Jaime José; TROMBETTA, Sérgio. Ética e direitos humanos: um olhar da Filosofia sobre desafios da educação contemporânea. In: HAMMES, Lúcio Jorge; SELAU, Bento (Orgs.). Educação, como estás? Debates na trama de temas emergentes. Lajeado: Ed. da Univates, 2011. p.103-113. 